\title{
Methylphenidate-Elicited Dopamine Increases in Ventral Striatum Are Associated with Long-Term Symptom Improvement in Adults with Attention Deficit Hyperactivity Disorder
}

\author{
Nora D. Volkow, ${ }^{1,2}$ Gene-Jack Wang, ${ }^{3}$ Dardo Tomasi, ${ }^{2}$ Scott H. Kollins, ${ }^{4}$ Tim L. Wigal, ${ }^{5}$ Jeffrey H. Newcorn, ${ }^{6}$ \\ Frank W. Telang, ${ }^{2}$ Joanna S. Fowler, ${ }^{3}$ Jean Logan, ${ }^{3}$ Christopher T. Wong, ${ }^{2}$ and James M. Swanson ${ }^{4}$ \\ ${ }^{1}$ National Institute on Drug Abuse, Bethesda, Maryland 20892, ${ }^{2}$ Laboratory of Neuroimaging, National Institute on Alcohol Abuse and Alcoholism, \\ Bethesda, Maryland 20892, ${ }^{3}$ Medical and Chemistry Departments, Brookhaven National Laboratory, Upton, New York 11973, ${ }^{4}$ Department of Psychiatry, \\ Duke University, Durham, North Carolina 27710, ${ }^{5}$ Child Development Center, University of California, Irvine, Irvine, California 92612, and ${ }^{6}$ Department of \\ Psychiatry, Mount Sinai Medical Center, New York, New York 10029
}

Stimulant medications, such as methylphenidate, which are effective treatments for attention deficit hyperactivity disorder (ADHD), enhance brain dopamine signaling. However, the relationship between regional brain dopamine enhancement and treatment response has not been evaluated. Here, we assessed whether the dopamine increases elicited by methylphenidate are associated with long-term clinical response. We used a prospective design to study 20 treatment-naive adults with ADHD who were evaluated before treatment initiation and after 12 months of clinical treatment with a titrated regimen of oral methylphenidate. Methylphenidate-induced dopamine changes were evaluated with positron emission tomography and $\left[{ }^{11} \mathrm{C}\right]$ raclopride $\left(\mathrm{D}_{2} / \mathrm{D}_{3}\right.$ receptor radioligand sensitive to competition with endogenous dopamine). Clinical responses were assessed using the Conners' Adult ADHD Rating Scale and revealed a significant reduction in symptoms of inattention and hyperactivity with long-term methylphenidate treatment. A challenge dose of $0.5 \mathrm{mg} / \mathrm{kg}$ intravenous methylphenidate significantly increased dopamine in striatum (assessed as decreases in $\mathrm{D}_{2} / \mathrm{D}_{3}$ receptor availability). In the ventral striatum, these dopamine increases were associated with the reductions in ratings of symptoms of inattention with clinical treatment. Statistical parametric mapping additionally showed dopamine increases in prefrontal and temporal cortices with intravenous methylphenidate that were also associated with decreases in symptoms of inattention. Our findings indicate that dopamine enhancement in ventral striatum (the brain region involved with reward and motivation) was associated with therapeutic response to methylphenidate, further corroborating the relevance of the dopamine reward/motivation circuitry in ADHD. It also provides preliminary evidence that methylphenidate-elicited dopamine increases in prefrontal and temporal cortices may also contribute to the clinical response.

\section{Introduction}

Attention deficit hyperactivity disorder (ADHD), which is characterized by symptoms of hyperactivity/impulsivity and inattention, affects $\sim 10 \%$ of children (National Institutes of Health,

Received Aug. 31, 2011; revised 0ct. 14, 2011; accepted Nov. 7, 2011.

Author contributions: N.D.V., G.J.W., D.T., S.H.K., T.L.W., J.H.N., F.W.T., J.S.F., J.L., and J.S. designed research; N.D.V., G.-J.W., D.T., S.H.K., T.L.W., J.H.N., F.W.T., J.S.F., and J.L. performed research; C.T.W. contributed unpublished reagents/analytic tools; N.D.V. and C.T.W. analyzed data; N.D.V. wrote the paper.

This research was supported in part by the Intramural Research Program of the National Institutes of Health (National Institute on Alcoholism and Alcohol Abuse), National Institute of Mental Health Grant R01MH66961 (G.-J.W.), with infrastructure support from U.S. Department of Energy/Office of Biological and Environmental Research Grant DE-AC02-76CH00016. We thank the following: David Schlyer and Michael Schueller for cyclotron operations; Donald Warner, David Alexoff, and Paul Vaska for PET operations; Richard Ferrieri, Colleen Shea, Youwen $\mathrm{Xu}$, Lisa Muench, and Payton King for radiotracer preparation and analysis, Karen Apelskog-Torres for study protocol preparation; Millard Jayne, Joseph English, Allan Chrisman, Barbara Hubbard, and Pauline Carter for patient care; and Ruben Baler and Denise Pintello for editorial assistance. This paper was presented at the Society of Nuclear Medicine in 2011.

Correspondence should be addressed to Dr. Nora D. Volkow, National Institute on Drug Abuse, 6001 Executive Boulevard, Room 5274, Bethesda, MD 20892. E-mail: nvolkow@nida.nih.gov.

DOI:10.1523/JNEUROSCI.4461-11.2012

Copyright $\odot 2012$ the authors $\quad 0270-6474 / 12 / 320841-09 \$ 15.00 / 0$
2000 ) and 5\% of adults (Fayyad et al., 2007) in the United States. Disrupted dopamine (DA) neurotransmission has been implicated in its pathophysiology (Volkow et al., 2007; Prince, 2008). The stimulants drugs methylphenidate (MP) and amphetamine are the primary medications used to treat ADHD (Ilgenli et al., 2007; Rubia et al., 2009), and both enhance DA signaling in brain (Kuczenski and Segal, 1997), which could account for their therapeutic effects. MP increases DA by blocking dopamine transporters (DATs) and amphetamine by releasing DA from the terminal using the DAT as carrier (Kuczenski and Segal, 1997). However, the relationship between DA increases elicited by stimulant medications and the response to clinical treatment in ADHD individuals is not known. The purpose of this study was to investigate whether the magnitude of the DA increases induced by an acute challenge with intravenous MP predicted the clinical response to long-term treatment with oral MP.

For this purpose, we studied 20 never-medicated adult ADHD subjects, who we treated prospectively over 12 months with a titrated regimen of oral MP. The DA increases to the acute MP 
Table 1. Demographic and clinical characteristic of participants

\begin{tabular}{llr}
\hline & Treatment-naive & $\begin{array}{r}\text { Long-term } \\
\text { treatment }\end{array}$ \\
\hline Age (years) & $32 \pm 6$ & \\
Gender & 12 female, 8 male & \\
Education (years) & $15 \pm 2$ & \\
BMl & $25 \pm 3$ & \\
Current smokers & 2 & \\
CAARS A & $26 \pm 6$ & $11 \pm 8^{*}$ \\
CAARS B & $22 \pm 9$ & $8 \pm 6^{*}$ \\
CAARS C & $19 \pm 7$ & $8 \pm 7^{*}$ \\
CAARS D & $9 \pm 4$ & $4 \pm 4^{*}$ \\
CAARS E & $20 \pm 4$ & $7 \pm 5^{*}$ \\
CAARS F & $15 \pm 6$ & $6 \pm 4^{*}$ \\
CAARS G & $36 \pm 6$ & $13 \pm 7^{*}$ \\
CAARS H & $21 \pm 4$ & $9 \pm 7^{*}$
\end{tabular}

Scores of the CAARS were obtained before treatment initiation (treatment-naive) and at the end of 12 month continuous treatment with oral methylphenidate (long-term treatment). Values correspond to means \pm SDs. ${ }^{*} p<0.0001$, repeated ANOVA for treatment-naive versus long-term treatment.

challenge were assessed using positron emission tomography (PET) with $\left[{ }^{11} \mathrm{C}\right]$ raclopride $\left(\mathrm{DA} \mathrm{D}_{2} / \mathrm{D}_{3}\right.$ receptor radioligand whose specific binding is sensitive to competition by endogenous DA) (Dewey et al., 1993). DA changes were assessed as the differences in the specific binding of $\left[{ }^{11} \mathrm{C}\right]$ raclopride after placebo and after an intravenous challenge with MP $(0.5 \mathrm{mg} / \mathrm{kg})$, which mostly reflect MP-induced DA increases (Volkow et al., 1994). We used intravenous rather than oral MP as a pharmacological challenge, because intravenous MP induces more robust and consistent DA responses that when it is given orally (Wang et al., 1999; Volkow et al., 2004). The DA measures were done twice: before initiation of treatment (treatment-naive) and after the 12 months of treatment (long-term treatment) with a titrated regimen of oral MP ( $\sim 1 \mathrm{mg} / \mathrm{kg}$ per day). Clinical symptoms of ADHD were measured using the Conners' Adult ADHD Rating Scale (CAARS) long version (Conners, 1998), also administered before treatment initiation and after 1 year of treatment. Based on our previous finding showing that reduced synaptic DA markers in ventral striatum (VS) (location of the nucleus accumbens) in ADHD were correlated with inattention (Volkow et al., 2009), we hypothesized that the magnitude of the DA increases in VS to MP challenge would predict clinical response to therapeutic doses of oral MP.

\section{Materials and Methods}

Subjects. We completed assessments in 20 never-medicated adult ADHD subjects ( 12 females, 8 males) (Table 1 provides clinical and demographic characteristics). ADHD subjects were recruited from clinical referrals to the ADHD programs at Mount Sinai School of Medicine (MSSM), Duke University, and University of California, Irvine (UCI). At least two clinicians interviewed the patients to ensure that they met the Diagnostic and Statistical Manual IV (DSM-IV) diagnostic criteria for ADHD, as evidenced by the presence of at least six of nine inattention symptoms (with or without six of nine hyperactive/impulsive symptoms) as ascertained with a semi-structured interview using DSM-IV criteria. In addition, evidence was required from each subject's history that some symptoms of ADHD were present in childhood (before age 7 years) even when the diagnosis was not made until adulthood. Subjects were excluded if they had a previous history of $>3$ months of medication treatment for ADHD and excluded if this short treatment occurred within the 6 months before the study.

Because it is estimated that only $10 \%$ of adults in the U.S. population meeting the criteria for ADHD are treated at any given time (Kessler et al., 2006), this exclusion criteria did not pose a selection bias. Participants were also excluded if they had a present or past history of substance abuse or dependence (except nicotine; only two participants were smokers). To ascertain past history of substance abuse, participants were asked about present or past substance abuse and underwent urine drug toxicological tests to ensure absence of drug use both at the time of screening and before the PET scan evaluations. Exclusion criteria also included present or past history of a DSM-IV Axis I or II diagnosis (other than ADHD) or neurological disease, medical conditions that may alter cerebral function (i.e., cardiovascular, endocrinological, oncological, or autoimmune diseases), current use of prescribed or over-the-counter medications, and/or head trauma with loss of consciousness of $>30 \mathrm{~min}$. All subjects had Hamilton Anxiety (Hamilton, 1959) and Hamilton Depression (Hamilton, 1960) scores $<19$. Urine drug screens were obtained on all subjects the day of the PET scan to check for psychoactive drug use. Written informed consent was obtained after complete description of the study to the subjects. Studies were approved by the Institutional Review Boards at Stony Brook University/Brookhaven National Laboratory, MSSM, UCI, and Duke University School of Medicine.

Clinical scales. We measured clinical symptoms using the CAARS long version, which provides self-assessment of ADHD symptoms on a 0 (not at all) to 3 (very much) point scale on eight subscales (A, inattention/ memory problems; $\mathrm{B}$, hyperactivity/restlessness; C, impulsivity/emotional liability; D, problems with self-concept; E, DSM-IV inattentive symptoms; F, DSM-IV hyperactive-impulsive symptoms; G, DSM-IV symptom total; and H, ADHD index) (Conners, 1998). Scores on the CAARS A, CAARS B, and CAARS $G$ were used to assess the correlations between symptom changes by clinical treatment with MP and the magnitude of the brain DA increases induced by intravenous MP. We restricted correlations to three subscales to limit the number of analyses (also subscales A and E, and subscales B and F include overlapping symptoms). The subscales for inattention and hyperactivity were chosen because they represent the core symptoms of ADHD, and the symptom total subscale was chosen as a measure of severity. Symptom improvement was quantified as the difference in the scores of the CAARS (CAARS A for inattention, CAARS B for hyperactivity, and CAARS $\mathrm{H}$ for symptom total) for the measures taken before treatment initiation (treatmentnaive) and those after long-term treatment with oral MP (within the week before the scanning session).

Study design. Participants had two sets of PET $\left[{ }^{11} \mathrm{C}\right]$ raclopride scans (with placebo and with intravenous MP): one before treatment initiation (treatment-naive) and one after 12 months of clinical treatment with oral MP (long-term treatment). Clinical treatment with oral MP was provided during the intervening 12 months between scanning sessions. The mean total daily dose of MP was in the vicinity of $1 \mathrm{mg} / \mathrm{kg}$ or its equivalent in long-acting dose form [i.e., osmotic release oral system (OROS) MP]. Participants were titrated to a mean dose of $75 \mathrm{mg}$. The dose is above the maximum labeled dose of OROS MP, because titration was managed according to clinical best practice to maximize efficacy. Progress of treatment was followed using the clinical global impressions improvement and severity scales (Guy, 2000) at each medication visit. Subjects were titrated in open manner during weekly medication visits until they reached optimal response and the dose was stabilized. The PET scans for the long-term treatment condition were conducted 24-48 $\mathrm{h}$ after the last clinical dose of MP to allow for the levels of MP from the final dose to dissipate before the PET study (Modi et al., 2000). To corroborate this, we measured plasma MP levels before intravenous injection of MP to ensure that they were nondetectable.

Scans. PET scans were obtained with a Siemens HR + tomograph [resolution, $4.5 \times 4.5 \times 4.5 \mathrm{~mm}$ full-width half-maximum $(\mathrm{FWHM})]$ in $3 \mathrm{D}$ mode. Each subject underwent two sets of paired scans with $\left[{ }^{11} \mathrm{C}\right]$ raclopride (total of four scans); for each set, one scan was done after intravenous placebo ( 3 cc saline) and one after intravenous MP $(0.5 \mathrm{mg} / \mathrm{kg})$. The study used a single blind design (subjects were blind to the drugs received). Dynamic scans were started immediately after injection of 4-8 $\mathrm{mCi}$ of $\left[{ }^{11} \mathrm{C}\right]$ raclopride (specific activity, $0.5-1.5 \mathrm{Ci} / \mu \mathrm{M}$ at end of bombardment). Dynamic scans were obtained for a total of $60 \mathrm{~min}$ as described previously (Volkow et al., 1994). Arterial blood was obtained throughout the procedure to measure the concentration of unchanged $\left[{ }^{11} \mathrm{C}\right]$ raclopride in plasma (Alexoff et al., 1995).

Image analysis and statistics. Regions of interest (ROIs) were obtained directly from the $\left[{ }^{11} \mathrm{C}\right]$ raclopride images as described previously 
Table 2. Measures of $K_{1}$ and of $\mathrm{D}_{2} / \mathrm{D}_{3}$ receptor availability $\left(\mathrm{BP}_{\mathrm{ND}}\right)$ in striatal regions and prefrontal cortex obtained with the $\mathrm{ROI}$ analysis for the treatment-naive and longterm treatment conditions

\begin{tabular}{|c|c|c|c|c|c|c|}
\hline & \multicolumn{2}{|l|}{$K_{1}$} & \multicolumn{2}{|l|}{$\mathrm{BP}_{\mathrm{ND}}$} & \multirow[b]{2}{*}{ Placebo versus i.v. MP } & \multirow[b]{2}{*}{ Naive versus long-term } \\
\hline & Placebo & i.v. MP & Placebo & i.v. MP & & \\
\hline \multicolumn{7}{|c|}{ Naive treatment } \\
\hline Caudate & $0.11 \pm 0.02$ & $0.11 \pm 0.02$ & $2.95 \pm 0.34$ & $2.59 \pm 0.37$ & $p<0.0001$ & \\
\hline Putamen & $0.13 \pm 0.02$ & $0.12 \pm 0.02$ & $3.64 \pm 0.28$ & $2.66 \pm 0.28$ & $p<0.0001$ & \\
\hline VS & $0.12 \pm 0.02$ & $0.11 \pm 0.02$ & $3.11 \pm 0.49$ & $2.54 \pm 0.55$ & $p<0.0001$ & \\
\hline Prefrontal & $0.12 \pm 0.03$ & $0.12 \pm 0.03$ & $0.13 \pm 0.11$ & $0.09 \pm 0.11$ & $p<0.03$ & \\
\hline \multicolumn{7}{|c|}{ Long-term treatment } \\
\hline Caudate & $0.12 \pm 0.01$ & $0.11 \pm 0.01$ & $2.66 \pm 0.36^{*}$ & $2.51 \pm 0.40$ & NS & NS \\
\hline Putamen & $0.13 \pm 0.02$ & $0.13 \pm 0.02$ & $3.30 \pm 0.50^{*}$ & $2.69 \pm 0.43$ & $p<0.0001$ & $p<0.005$ \\
\hline VS & $0.13 \pm 0.02$ & $0.12 \pm 0.02$ & $2.97 \pm 0.47$ & $2.54 \pm 0.56$ & $p<0.05$ & $p<0.07$ \\
\hline Prefrontal & $0.13 \pm 0.02$ & $0.12 \pm 0.02$ & $0.15 \pm 0.08$ & $0.10 \pm 0.06$ & $p<0.001$ & NS \\
\hline
\end{tabular}

Comparisons correspond to repeated ANOVA for drug (placebo vs intravenous MP) and for condition (treatment-naive vs long-term treatment). ${ }^{*} p<0.006$, post hoc comparisons showed significantly lower $D_{2} / D_{3}$ receptor availability after placebo for the long-term treatment than for the treatment-naive condition. The $K_{1}$ measures did not differ between placebo and intravenous MP or between naive and long-term treatment conditions. i.v. Intravenous.

(Volkow et al., 1994). Briefly, we identified the ROI on summed images (dynamic images taken from 10 to $54 \mathrm{~min}$ ) that were resliced along the intercommissural plane (anterior commissure-posterior commissure line). The caudate, putamen, VS, and cerebellum were measured on four, three, two, and two planes, respectively, and right and left regions were delineated. These regions were then projected to the dynamic scans to obtain concentrations of carbon-11 versus time, which were used to calculate the $K_{1}$ (transport constant from plasma to tissue) and the distribution volumes (milliliters per grams) and the blood to tissue transport constant $\left(K_{1}\right)$ in caudate, putamen, VS, and cerebellum using a graphical analyses technique for reversible systems (Logan plots) (Logan et al., 1990). The measure of binding potential relative to a nondisplaceable reference $\left(\mathrm{BP}_{\mathrm{ND}}\right)$ was obtained as the ratio of the distribution volume in striatum to that in cerebellum minus 1 and was used to quantify DA $\mathrm{D}_{2} / \mathrm{D}_{3}$ receptor availability. The difference in $\mathrm{BP}_{\mathrm{ND}}$ between $\mathrm{MP}$ and placebo $\left(\Delta \mathrm{BP}_{\mathrm{ND}}\right)$ was used as the measure of DA release. A two-measure within-subject repeated ANOVA to assess for drug effect (placebo vs intravenous MP) and condition (treatment-naive vs long-term treatment) was done to evaluate the effects of intravenous MP on DA and to determine whether this effect was influenced by long-term clinical treatment with oral MP. Pearson's product moment correlation analysis was done to assess whether DA changes were associated with symptom changes while on treatment [difference on the scores for inattention (CAARS A), hyperactivity (CAARS B), and total symptoms (CAARS G) obtained before treatment initiation and those after long-term clinical treatment with oral MP]. To control for potential nonspecific effects of intravenous MP, we also evaluated its effects on $K_{1}$ and assessed the correlation between changes in $K_{1}$ (placebo vs intravenous MP) and symptom improvement while on treatment. To control for the contribution of depression and anxiety on MP-induced DA changes, we included the Hamilton scores as covariates in the analyses.

Findings with the ROI analysis were considered significant only if corroborated with Statistical Parametric Mapping (SPM) (Friston et al., 1995). SPM was also used for exploratory analysis to assess the effects of intravenous MP on DA release in extrastriatal brain regions. The SPM analysis was performed on $\mathrm{BP}_{\mathrm{ND}}$ images (obtained by computing the $\mathrm{BP}_{\mathrm{ND}}$ in each pixel). A spatial normalization template matching the average $\mathrm{BP}_{\mathrm{ND}}$ image contrast in the brain was developed using the $\mathrm{BP}_{\mathrm{ND}}$ images from 34 healthy control subjects that participated in previous $\left[{ }^{11} \mathrm{C}\right]$ raclopride studies and collected with the same instrument and scanning sequence used for the present study. All images were carefully inspected to ensure whole-brain coverage and exclude images with potential artifacts. A 12-parameter affine transformation with 16 nonlinear iterations was used to register the images to the PD.mnc Montreal Neurological Institute (MNI) template provided with the SPM2 package. The dimensions of the bounding box of the output volumes were 90:90, $126: 90$, and 72:108 along $x, y$, and $z$, respectively, and the voxel size was $2 \times 2 \times 2 \mathrm{~mm}^{3}$. Bilinear interpolation was used for image reslicing. The average normalized and smoothed image (FWHM, $8 \mathrm{~mm}$ ) was computed to obtain the $\mathrm{BP}_{\mathrm{ND}}$ template in the MNI stereotactic space. The $\mathrm{BP}_{\mathrm{ND}}$ images of the present study were then spatially normalized to the

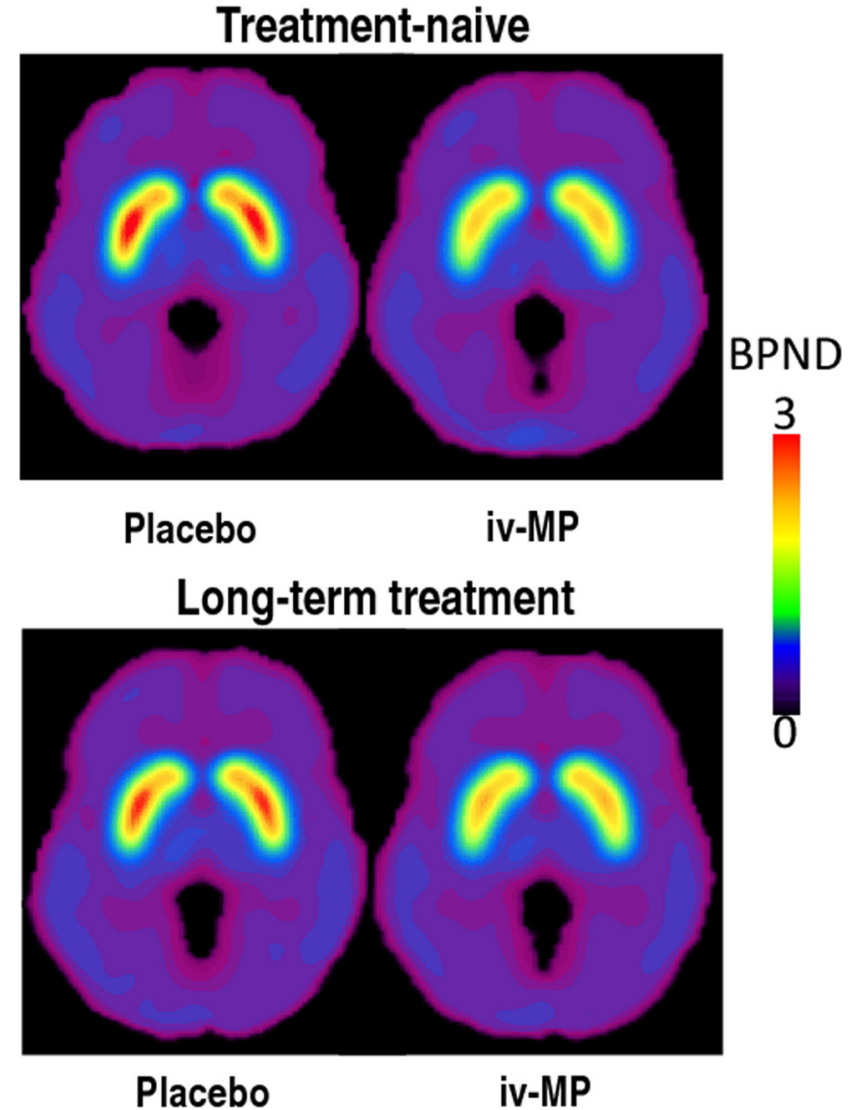

Figure 1. Averaged $D A D_{2} / D_{3}$ receptor availability $\left(\mathrm{BP}_{\mathrm{ND}}\right)$ images for the $\left[{ }^{11} \mathrm{C}\right]$ raclopride scans done after intravenous placebo and after intravenous MP (iv-MP) for the treatment-naive and long-term treatment conditions. Intravenous $M P$ reduced $D A D_{2} / D_{3}$ receptor availability in striatum in both conditions, reflecting the DA increases elicited by the drug.

stereotactic space of MNI using the $\mathrm{BP}_{\mathrm{ND}}$ template and subsequently smoothed with an $8 \mathrm{~mm}$ isotropic Gaussian kernel. A within-subject ANOVA model in SPM2 was used to assess for drug effect (placebo vs intravenous MP) and treatment condition (treatment-naive vs longterm treatment) to assess the effects of intravenous MP on DA and to determine whether this effect was affected by long-term clinical MP treatment. Significance was set at $p<0.001$ (uncorrected, cluster size threshold $>100$ voxels), and the statistical maps were overlaid on an MRI structural image. Pearson's product moment correlations were used to assess the association between MP-induced DA changes $\left(\Delta \mathrm{BP}_{\mathrm{ND}}\right.$ intravenous MP vs placebo) and the changes in the scores on the CAARS A 


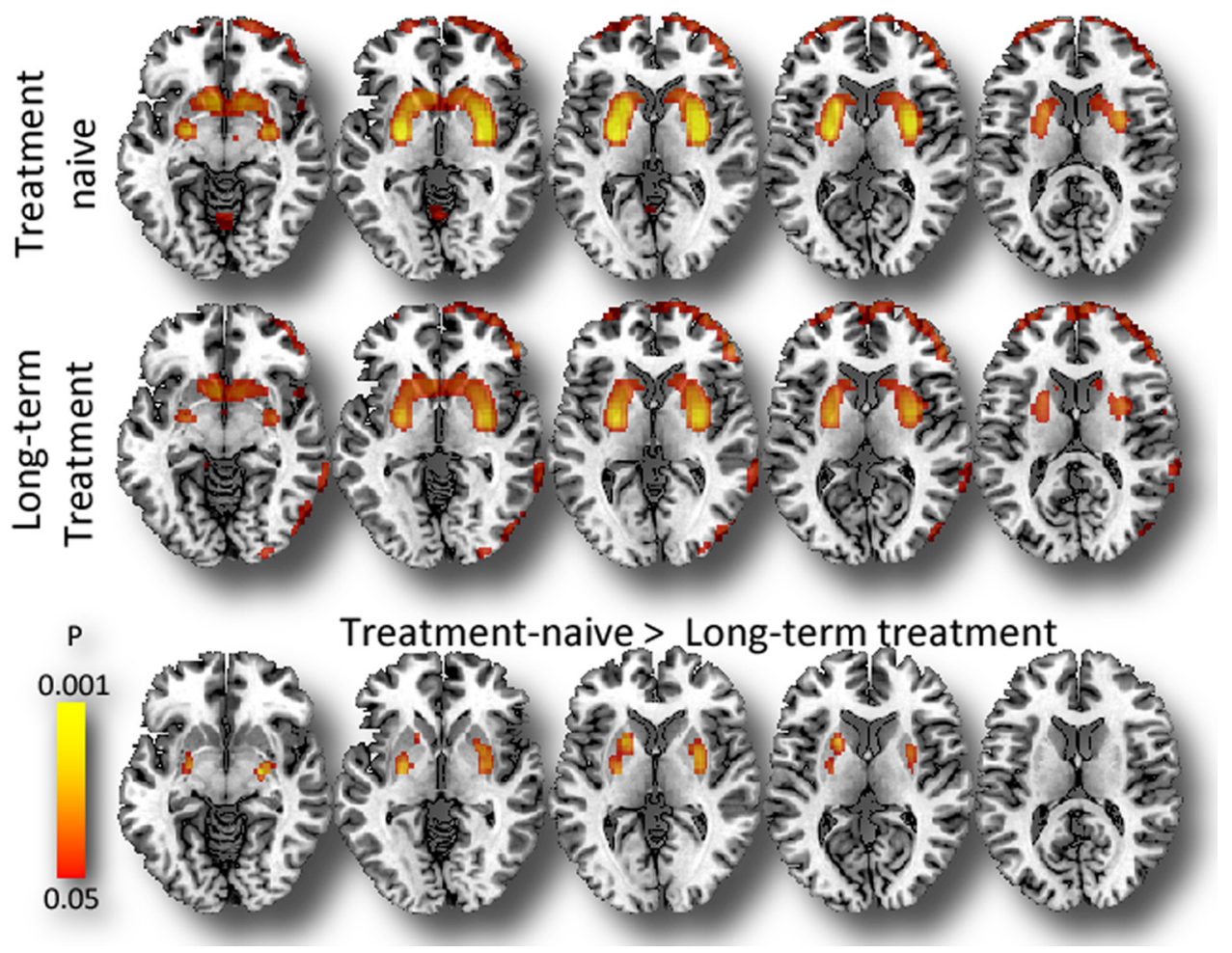

Figure 2. SPM results for the effects of intravenous $M P$ on $D A D_{2} / D_{3}$ receptor availability $\left(\mathrm{BP}_{\mathrm{ND}}\right)$ for the measures made for the treatment-naive and long-term treatment conditions and $S P M$ results for the comparisons between treatment-naive and long-term treatment. $M P$ reduced $D A D_{2} / D_{3}$ receptor availability in striatal regions and also in frontal and temporal cortices. The reductions in $\mathrm{DA}_{2} / \mathrm{D}_{3}$ receptor availability induced by intravenous $\mathrm{MP}$ were significantly greater for the treatment-naive than for the long-term treatment condition in striatal regions but did not differ in cortical regions.

(inattention) and CAARS B (hyperactivity) ( $\Delta$ treatment-naive vs longterm treatment).

\section{Results}

Plasma concentration after intravenous MP challenge

Plasma levels of MP were undetectable before the injection of intravenous MP both in the treatment-naive and long-term treatment conditions. After intravenous MP injection, there were no differences in plasma MP concentrations (nanograms per milliliters) between the treatment-naive and long-term treatment conditions for any of the different time points: $15 \mathrm{~min}(132 \pm 34$ vs $134 \pm 32$, respectively), $30 \mathrm{~min}$ ( $96 \pm 17$ vs $93 \pm 26), 45 \mathrm{~min}$ ( $69 \pm 19$ vs $74 \pm 23)$, or $60 \mathrm{~min}(55 \pm 14$ vs $56 \pm 13)$.

\section{DA $D_{2}$ receptor availability with placebo}

The ROI analysis on the measures of $\mathrm{D}_{2} / \mathrm{D}_{3}$ receptor availability $\left(\mathrm{BP}_{\mathrm{ND}}\right.$ of $\left[{ }^{11} \mathrm{C}\right]$ raclopride) obtained with placebo (without intravenous MP) revealed higher $D_{2} / D_{3}$ receptor availability for the measures obtained before treatment initiation (treatmentnaive) than those obtained after long-term treatment with oral MP, both for caudate $(p<0.005)$ and putamen $(p<0.006)$ but not for VS (Table 2). The SPM analysis showed the same trend ( $p<0.05$ uncorrected), although the effect was not significant when corrected for multiple comparisons with familywise error $\left(p_{\text {FWE-CORR }}>0.05\right)$.

Effects of intravenous MP on $K_{1}$ and $\mathrm{D}_{2} / \mathrm{D}_{3}$ receptor availability $\left(\mathrm{BP}_{\mathrm{ND}}\right)$ with intravenous $\mathrm{MP}$

Intravenous MP did not change $K_{1}$ (transport constant of radiotracer from plasma to tissue) in striatum for neither the naive nor long-term treatment condition (Table 2). Conversely, intravenous MP significantly reduced $D_{2} / D_{3}$ receptor availability in striatal regions (caudate, putamen, VS) (Fig. 1) (Table 2). Comparison between conditions revealed that the reductions in $\mathrm{BP}_{\mathrm{ND}}$ with intravenous $\mathrm{MP}$ were significantly higher for the treatment-naive than for the long-term treatment condition in putamen $(26 \pm 7$ vs $18 \pm 10 \%, p<0.01$, respectively) and showed a trend in VS (18 \pm 15 vs $9 \pm 15 \%$, $p<0.07)$; in caudate, the difference was not statistically significant ( $10 \pm 8$ vs $5 \pm 10 \%$ ) (Table 2 ).

The SPM analysis corroborated a significant decrease $\left(p_{\text {FWE-CORR }}<0.05\right)$ in striatal $\mathrm{D}_{2} / \mathrm{D}_{3}$ receptor availability with intravenous MP for both the treatment-naive and long-term treatment conditions (Fig. 2, Table 3) and corroborated the significantly larger decreases in $\mathrm{D}_{2} / \mathrm{D}_{3}$ receptor availability elicited by the intravenous MP challenge before treatment (treatment-naive) than after long-term treatment in putamen and VS (Fig. 2, Table 3).

In addition, the SPM analysis identified several extrastriatal regions in which the intravenous MP challenge significantly decreased $\mathrm{D}_{2} / \mathrm{D}_{3}$ receptor availability, including frontal and temporal cortical regions (Fig. 2, Table 3). The decreases in $\mathrm{D}_{2} / \mathrm{D}_{3}$ receptor availability in these cortical regions did not differ between the treatment-naive and long-term treatment conditions.

After the SPM findings, we extracted ROIs in prefrontal cortex and assessed the effects of intravenous MP on $K_{1}$ and in $\mathrm{D}_{2} / \mathrm{D}_{3}$ receptor availability and showed that, although intravenous MP did not affect $K_{1}$, it significantly decreased $\mathrm{D}_{2} / \mathrm{D}_{3}$ receptor availability (Table 2).

None of these findings was affected when we used as covariates the scores on the Hamilton's Depression and Anxiety scales. 
Table 3. SPM results showing the brain regions in which intravenous MP increased DA (decreased $D_{2} / D_{3}$ receptor availability) combined for treatment-naive and long-term treatments and SPM results showing the brain regions in which the DA increases induced by intravenous MP were larger for the naive than for the long-term treatment (Naive vs chronic)

\begin{tabular}{|c|c|c|c|c|c|c|c|c|}
\hline BA/nucleus & Cluster size & $x$ & $y$ & $z$ & $F$ value & $p_{\text {FWE-CORR }}$ & $T$ value & $p_{\text {uncorr }}$ \\
\hline \multicolumn{9}{|l|}{ Placebo versus MP } \\
\hline Striatum & 3721 & & & & & 0.000 & & \\
\hline R putamen & & 30 & -8 & 2 & 336 & & & \\
\hline L putamen & & -24 & -6 & 2 & & & & \\
\hline L ventral striatum & & -6 & 14 & -6 & & & & \\
\hline L inferior temporal & 3910 & & & & & 0.000 & & \\
\hline \multirow[t]{3}{*}{ BA 20} & & -28 & -14 & -46 & 61 & & & \\
\hline & & -58 & -58 & -32 & & & & \\
\hline & & -12 & -4 & -40 & & & & \\
\hline L middle frontal & 472 & & & & & 0.000 & & \\
\hline \multirow{2}{*}{ BA 11} & & -24 & 48 & -24 & 56 & & & \\
\hline & & -26 & 40 & -26 & & & & \\
\hline R inferior frontal & 2457 & & & & & 0.000 & & \\
\hline \multirow[t]{3}{*}{ BA 46} & & 50 & 44 & 2 & 56 & & & \\
\hline & & 42 & 54 & 14 & & & & \\
\hline & & 32 & 64 & 6 & & & & \\
\hline RUncus & 263 & & & & & 0.001 & & \\
\hline \multirow[t]{2}{*}{ BA 36} & & 30 & -14 & -44 & 46 & & & \\
\hline & & 14 & -6 & -36 & & & & \\
\hline R middle frontal & 331 & & & & & 0.006 & & \\
\hline \multirow[t]{3}{*}{ BA 11} & & 30 & 34 & -28 & 36 & & & \\
\hline & & 36 & 42 & -24 & & & & \\
\hline & & 32 & 26 & -36 & & & & \\
\hline \multirow[t]{2}{*}{ Midbrain } & 271 & 12 & -14 & -16 & 32 & 0.02 & & \\
\hline & & 4 & -10 & -16 & & & & \\
\hline \multicolumn{9}{|l|}{ Naive versus chronic } \\
\hline Striatum & 533 & & & & & & & \\
\hline L putamen & & -20 & 8 & 6 & & & 3.28 & 0.001 \\
\hline L ventral putamen & & -24 & -6 & -4 & & & 2.93 & 0.002 \\
\hline Striatum & 505 & & & & & & & \\
\hline R ventral striatum & & 24 & -10 & -8 & & & 2.89 & 0.002 \\
\hline R putamen & & 30 & -4 & 2 & & & 2.79 & 0.003 \\
\hline
\end{tabular}

For the naive versus long-term treatment comparison, all four coordinates have voxel-level $p<0.026$, corrected for multiple comparisons (familywise error). There were no regions in which the effect of intravenous MP was greater for long-term treatment than for the treatment-naive condition. L, Left; R, right.

\section{Correlations between brain DA measures and clinical responses to MP}

The prospective clinical treatment with MP was associated with a significant decrease in average ratings of ADHD symptoms. All scales of the CAARS were significantly higher before treatment initiation than after 1 year of treatment with the titrated regimen or oral MP (Table 1).

The ROI analysis revealed that the correlations between improvement in clinical symptoms with oral MP treatment (before treatment initiation vs after long-term treatment) and the DA increases elicited by intravenous MP (quantified as decreases in $\mathrm{D}_{2} / \mathrm{D}_{3}$ receptor availability) were significant for the measures obtained after long-term treatment but not with those obtained before treatment initiation (treatment-naive). Specifically, these correlations were significant for MP-induced DA increases in VS (but not for caudate or putamen) for the ratings of inattention (CAARS A, $r=0.70, p<0.001$ ) and showed a trend for ratings of hyperactivity (CAARS B, $r=0.50, p<0.03$ ) and total symptoms (CAARS G, $r=0.54, p<0.02$ ). Subjects with the larger DA increases in VS with intravenous MP had the greatest reduction in symptoms with long-term MP treatment.

The SPM results for the voxelwise analysis corroborated the significant correlation between DA increases elicited by intravenous MP in VS and the reduction in symptoms of inattention (CAARS A) after long-term treatment and also identified a significant correlation with DA increases in other striatal regions (caudate and putamen) and prefrontal (BA 8, BA 9, BA 24) and temporal (BA 22) cortices (Fig. 3, Table 4). However, the correlations with hyperactivity (CAARS B) or total symptoms (CAARS G) did not reach significance.

The correlations between the differences in $K_{1}$ (placebo vs intravenous MP) and improvement in clinical symptoms during treatment (changes in scores in CAARS A, CAARS B, CAARS G) were not significant for either striatal or cortical regions (for either naive or long-term treatment conditions).

\section{Discussion}

Here we report several new neurobiological findings about ADHD and MP. First, we show that intravenous MP-induced increases in brain DA were associated with degree of clinical response in a prospective clinical trial of oral MP. Furthermore, we showed that the DA increases in a crucial brain region for reward and motivation (the VS) were associated with improvement in symptoms of inattention. In addition, our SPM analyses showed evidence of MP-induced DA increases in prefrontal and temporal cortices that were also associated with decreases in ratings of inattention. Finally, we document an attenuation of MP-induced DA increases in striatum and a trend toward lower baseline levels of $\mathrm{D}_{2} / \mathrm{D}_{3}$ receptor availability in striatum after long-term treatment with oral MP.

\section{Effects of MP on striatal DA increases}

Our findings are consistent with previous $\left[{ }^{11} \mathrm{C}\right]$ raclopride studies in healthy controls (Volkow et al., 1997; Martinez et al., 2003) and in 
adolescents and adults with ADHD (RosaNeto et al., 2005; Volkow et al., 2007) showing that MP significantly increases DA in striatum. Historically, the core feature of ADHD has been characterized as one of an attention deficit, but increasing evidence suggests that a reward and motivation deficit may be of equal importance (Haenlein and Caul, 1987; Sonuga-Barke, 2003; Tripp and Wickens, 2008; Castellanos, 2009; Volkow et al., 2009). Indeed, we had proposed that MP, by increasing DA in VS (central brain region for motivation and reward; Wise, 2002) would enhance the saliency of the task, thus improving attention in ADHD (Volkow et al., 2001, 2004), and our current finding of a correlation between MP-induced DA increases in VS and reductions in inattention support this. They are also consistent with previous findings of an association between DA markers in the VS and symptoms of inattention and with reduced scores in a trait measure of motivation in adults with ADHD (Volkow et al., 2011). In ADHD, the decreased DA synthesis of adolescents in nucleus accumbens (located in VS) was also correlated with symptoms of inattention (Forssberg et al., 2006), suggesting that our findings may also pertain to adolescents with ADHD.

The correlations with ratings of hyperactivity were not corroborated by SPM, which may have reflected the low scores in symptoms of hyperactivity in our subjects. Alternatively, it could reflect involvement of noradrenergic effects in reducing hyperactivity (Tilley and $\mathrm{Gu}, 2008$ ).

\section{Effects of MP on extrastriatal DA increases}

Intravenous $\mathrm{MP}$ significantly reduced $\mathrm{D}_{2} / \mathrm{D}_{3}$ receptor availability in prefrontal and temporal cortices, presumably from DA increases. Although the accuracy of $\left[{ }^{11} \mathrm{C}\right]$ raclopride to measure DA changes in cortical regions is limited (Egerton et al., 2009), the consistency across both assessments and the high level of statistical significance suggest that these are reliable effects. Moreover, the lack of an effect of intravenous MP on $K_{1}$ suggests that decreased delivery of the radiotracer to the cortex did not contribute to the decrease in $\mathrm{D}_{2} / \mathrm{D}_{3}$ receptor availability. Indeed, others have reported DA increases in prefrontal and temporal cortices with drug challenges (tetrahydrocannabinol and methamphetamine) using $\left[{ }^{11} \mathrm{C}\right]$ raclopride (Piccini et al., 2003; Stokes et al., 2010). Moreover, a previous study showed that oral MP (0.63 mg/ $\mathrm{kg}$ ) increased DA in prefrontal and temporal cortices in controls using [ $\left.{ }^{11} \mathrm{C}\right] \mathrm{FLB} 457$ [( S)-5-bromo- $N$-[(1-ethyl-2-pyrrolidinyl)methyl]2,3-dimethoxybenzamide monohydrobromide] (Montgomery et al., 2007).

Decreases in $\mathrm{D}_{2} / \mathrm{D}_{3}$ receptor availability with intravenous MP in prefrontal and temporal cortices were associated with decreased ratings of inattention when subjects were clinically treated, which suggests that enhancement of DA signaling in these cortical regions may contribute to the therapeutic actions of oral MP. MP could ameliorate inattention by both enhancing saliency (through effects on VS) and enhancing the executive components of attention that are mediated through prefrontal regions (including cingulate gyrus) (Fan et al., 2005). Although prefrontal regions expresses low DAT levels (Sesack et al., 1998),
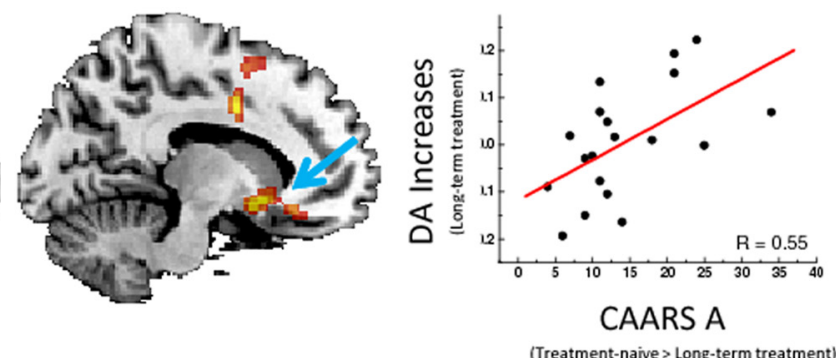

(Treatment-naive > Long-term treatment)
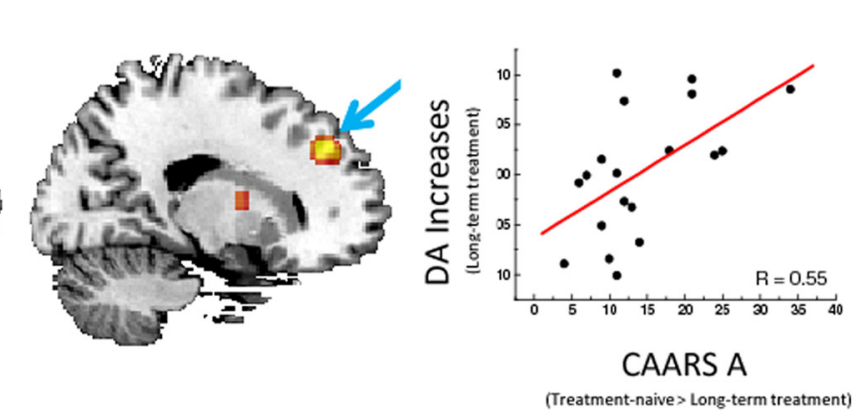

(Treatment-naive $>$ Long-term treatment)

Figure 3. SPM results for the voxelwise correlation between intravenous $M P$-induced changes in $D A D_{2} / D_{3}$ receptor availability $\Delta$ treatment-naive $>$ long-term treatment) shown in an axial and a sagittal plane at the levels where the VS $(\boldsymbol{A})$ and the prefrontal cortex $(\boldsymbol{B})$ are located along with the respective regression slopes for the ROls identified from SPM.

Table 4. SPM results for the location of the brain regions showing a significant positive correlation between the changes in CAARS A (inattention) with medication treatment (compared with measures obtained before treatment initiation) and the DA increases induced by intravenous MP obtained during the long-term treatment condition

\begin{tabular}{lllrrrrl}
\hline Region & BA/ & Cluster & & & & & \\
& nucleus & size & \multicolumn{1}{l}{$x$} & $y$ & $z$ & T value & $P_{\text {cluster-corr }}$ \\
\hline R medial frontal & BA 9 & 1063 & 18 & 38 & 36 & 5.85 & 0.000 \\
R medial frontal & BA 8 & & 0 & 26 & 44 & & \\
L cingulated & BA 24 & & -14 & 0 & 38 & & \\
L thalamus & & 527 & -38 & -30 & 2 & 5.47 & 0.003 \\
L superior temporal & BA 22 & & -46 & -24 & 6 & & \\
L superior temporal & BA 22 & & -60 & -34 & 12 & & \\
L caudate & BA 47 & 955 & -10 & 10 & -1 & 5.40 & 0.000 \\
L putamen & & & -38 & 8 & -20 & & \\
L inferior frontal & & & -40 & 16 & -24 & & \\
R putamen & & 629 & 40 & -4 & -2 & 5.05 & 0.001 \\
R putamen & & & 32 & 10 & 2 & & \\
R VS & & & 26 & 0 & -6 & &
\end{tabular}

L, Left; $R$, right.

MP also blocks norepinephrine transporters (Hannestad et al., 2010), which in prefrontal cortex contribute to DA reuptake and mediate DA increases (Carboni et al., 1990; Morón et al., 2002).

A key component of the DA-deficit theory of ADHD proposes that MP treatment enhances DA in the prefrontal cortex and this contributes to its therapeutic effects (Arnsten, 2009), and fMRI studies support this (Bush et al., 2008). Although much less investigated, there is also evidence of the involvement of temporal cortical regions in ADHD (Kobel et al., 2010) and on their sensitivity to MP (Rubia et al., 2009).

Effects of chronic treatment on MP-induced DA increases Long-term treatment with MP decreased MP-induced DA increases in striatum but not in cortex. MP increases DA by blocking DAT (Volkow et al., 2001; Spencer et al., 2006), which is the main mechanism for removal of DA from the extracellular space 
(Gainetdinov and Caron, 2003), and thus the magnitude of the DA increase is derived both by the level of DAT blockade and the amount of DA released (Volkow et al., 2002). Because MP blood levels are associated with the level of DAT blockade (Volkow et al., 1998) and the concentration of MP in plasma after intravenous MP did not differ for treatment-naive and long-term treatment conditions, the lower DA increases in striatum over the year of treatment suggest changes that decrease DA release. These reductions are likely to reflect neuroplasticity effects of chronic MP treatment rather than natural decline because, in healthy controls, DA increases induced by amphetamine were higher (not lower) when subjects were retested 12 months later without any therapeutic intervention (Boileau et al., 2006). This interpretation is consistent with some clinical findings that suggest tolerance to the beneficial effects of MP with long-term treatment, in follow-up studies of ADHD cohorts (Swanson et al., 2008; Molina et al., 2009).

The mechanism(s) that may result in reduced striatal DA release with chronic MP are unclear. They could reflect increased sensitivity of DA autoreceptors that inhibit DA release (Aghajanian and Bunney, 1977) or upregulation of DATs that remove extracellular DA (Gainetdinov and Caron, 2003). Decreases could also reflect adaptations in cortical regions that regulate DA release (i.e., frontostriatal pathways) (Karreman and Moghaddam, 1996). Because the attenuation was in striatum and not in cortical regions, this suggests that they reflect changes in DA autoreceptor sensitivity and/or DAT upregulation because cortical DA projections are much less sensitive to regulation by DA autoreceptors or DAT (Lammel et al., 2008). Indeed, we recently showed that 12 month treatment with oral MP resulted in upregulation of DAT in striatum (Wang et al., 2009).

The ROI analysis revealed that baseline measures of $\mathrm{D}_{2} / \mathrm{D}_{3}$ receptor availability in dorsal striatum (placebo measures) were lower after long-term treatment with oral MP than before treatment (treatment-naive), but SPM did not corroborate this unless we decreased significance to $p_{\text {uncorr }}<0.05$. Thus, larger samples are needed to confirm this. Baseline measures of $\mathrm{D}_{2} / \mathrm{D}_{3}$ receptor availability in putamen (naive condition) were higher than those we reported in another group of naive ADHD adults (3.64 vs 3.44) but similar to the controls from that study (3.63) (Volkow et al., 2007). These differences are likely to reflect intersubject variability as well as noncontrolled variables that influence $\mathrm{D}_{2} / \mathrm{D}_{3}$ receptor availability (i.e., sleep deprivation) (Volkow et al., 2008).

\section{Limitations}

Changes in $\left[{ }^{11} \mathrm{C}\right]$ raclopride binding are related to extracellular DA, but the relationship with synaptic DA is not completely understood (Gjedde et al., 2005). The $\left[{ }^{11} \mathrm{C}\right]$ raclopride method is best suited for regions with high $\mathrm{D}_{2} / \mathrm{D}_{3}$ receptor density, such as striatum, and much less sensitive to cortical regions, which renders our cortical findings as preliminary. ROIs were obtained directly from the $\left[{ }^{11} \mathrm{C}\right]$ raclopride images and not from MRIs but, because measures of $\mathrm{D}_{2} / \mathrm{D}_{3}$ receptor availability obtained using ROIs selected directly from $\left[{ }^{11} \mathrm{C}\right]$ raclopride images do not differ from those selected from the subject's MRIs (Wang et al., 1996), this is unlikely to have influenced our findings. We show dampening of the DA-enhancing effects of MP after long-term treatment, but we cannot determine whether this is associated with tolerance to clinical efficacy, whether it is long lasting or dissipates promptly. Because of ethical reasons, we did not use a group of untreated ADHD controls to rule out the possibility that the attenuation reflects an age-related decline. To assess clinical efficacy, we did not use a measure of cognitive performance because we were interested in assessing the relationship between enhancement of DA signaling by MP and symptom improvement, which is why we selected the CAARS, an instrument with extensive validity for its use to monitor treatment response in ADHD (Rösler et al., 2010). In our study, we did not obtain measures of motivation, which would have allowed us to test whether DA increases in VS were associated with increased motivation while on clinical treatment. Finally, this study focused on DA, and future studies are necessary to evaluate the noradrenergic effects of MP.

In summary, we show an association between the DA increases elicited by a challenge with intravenous MP in the VS and the improvement in ratings of inattention with long-term oral MP treatment, which provides evidence that the enhancement of DA signaling by MP in VS (a key brain region involved with reward and motivation) is involved in its therapeutic benefits in ADHD. We also give preliminary evidence that MP increases DA in prefrontal and temporal cortices, which may be therapeutically relevant, and that chronic treatment with oral MP may result in adaptations in striatal DA signaling.

\section{References}

Aghajanian GK, Bunney BS (1977) Dopamine "autoreceptors": pharmacological characterization by microiontophoretic single cell recording studies. Naunyn Schmiedebergs Arch Pharmacol 297:1-7.

Alexoff DL, Shea C, Fowler JS, King P, Gatley SJ, Schlyer DJ, Wolf AP (1995) Plasma input function determination for PET using a commercial laboratory robot. Nucl Med Biol 22:893-904.

Arnsten AF (2009) Toward a new understanding of attention-deficit hyperactivity disorder pathophysiology: an important role for prefrontal cortex dysfunction. CNS Drugs 23 [Suppl 1]:33-41.

Boileau I, Dagher A, Leyton M, Gunn RN, Baker GB, Diksic M, Benkelfat C (2006) Modeling sensitization to stimulants in humans: an $\left[{ }^{11} \mathrm{C}\right]$ raclopride/positron emission tomography study in healthy men. Arch Gen Psychiatry 63:1386-1395.

Bush G, Spencer TJ, Holmes J, Shin LM, Valera EM, Seidman LJ, Makris N, Surman C, Aleardi M, Mick E, Biederman J (2008) Functional magnetic resonance imaging of methylphenidate and placebo in attention-deficit/ hyperactivity disorder during the multi-source interference task. Arch Gen Psychiatry 65:102-114.

Carboni E, Tanda GL, Frau R, Di Chiara G (1990) Blockade of the noradrenaline carrier increases extracellular dopamine concentrations in the prefrontal cortex: evidence that dopamine is taken up in vivo by noradrenergic terminals. J Neurochem 55:1067-1070.

Castellanos FX (2009) Toward the dimensionome: parsing reward-related processing in attention-deficit/hyperactivity disorder. Biol Psychiatry 65:5-6.

Conners CK (1998) Rating scales in attention-deficit/hyperactivity disorder: use in assessment and treatment monitoring. J Clin Psychiatry 59 [Suppl 7]:24-30.

Dewey SL, Smith GS, Logan J, Brodie JD, Fowler JS, Wolf AP (1993) Striatal binding of the PET ligand 11C-raclopride is altered by drugs that modify synaptic dopamine levels. Synapse 13:350-356.

Egerton A, Mehta MA, Montgomery AJ, Lappin JM, Howes OD, Reeves SJ, Cunningham VJ, Grasby PM (2009) The dopaminergic basis of human behaviors: a review of molecular imaging studies. Neurosci Biobehav Rev 33:1109-1132.

Fan J, McCandliss BD, Fossella J, Flombaum JI, Posner MI (2005) The activation of attentional networks. Neuroimage 26:471-479.

Fayyad J, De Graaf R, Kessler R, Alonso J, Angermeyer M, Demyttenaere K, De Girolamo G, Haro JM, Karam EG, Lara C, Lépine JP, Ormel J, PosadaVilla J, Zaslavsky AM, Jin R (2007) Cross-national prevalence and correlates of adult attention-deficit hyperactivity disorder. Br J Psychiatry 190:402-409.

Forssberg H, Fernell E, Waters S, Waters N, Tedroff J (2006) Altered pattern of brain dopamine synthesis in male adolescents with attention deficit hyperactivity disorder. Behav Brain Funct 2:40.

Friston K, Holmes A, Worsley K, Poline J, Frith C, Frackowiak R (1995) Statistical parametric maps in functional imaging: a general linear approach. Hum Brain Mapp 2:189-210. 
Gainetdinov RR, Caron MG (2003) Monoamine transporters: from genes to behavior. Annu Rev Pharmacol Toxicol 43:261-284.

Gjedde A, Wong DF, Rosa-Neto P, Cumming P (2005) Mapping neuroreceptors at work: on the definition and interpretation of binding potentials after 20 years of progress. Int Rev Neurobiol 63:1-20.

Guy W (2000) Clinical global impression (CGI) scale. In: Handbook of psychiatric measures (Rush AJ, First MB, Blacker D, eds). Washington, DC: American Psychiatric Publishing.

Haenlein M, Caul WF (1987) Attention deficit disorder with hyperactivity: a specific hypothesis of reward dysfunction. . J Am Acad Child Adolesc Psychiatry 26:356-362.

Hamilton M (1959) The assessment of anxiety states by rating. Br J Med Psychol 32:50-55.

Hamilton M (1960) A rating scale for depression. J Neurol Neurosurg Psychiatry 23:56-62.

Hannestad J, Gallezot JD, Planeta-Wilson B, Lin SF, Williams WA, van Dyck CH, Malison RT, Carson RE, Ding YS (2010) Clinically relevant doses of methylphenidate significantly occupy norepinephrine transporters in humans in vivo. Biol Psychiatry 68:854-860.

Ilgenli TF, Congologlu A, Ozturk C, Turkbay T, Akpinar O, Kilicaslan F (2007) Acute effect of methylphenidate on QT interval duration and dispersion in children with attention deficit hyperactivity disorder. Adv Ther 24:182-188.

Karreman M, Moghaddam B (1996) The prefrontal cortex regulates the basal release of dopamine in the limbic striatum: an effect mediated by ventral tegmental area. J Neurochem 66:589-598.

Kessler RC, Adler L, Barkley R, Biederman J, Conners CK, Demler O, Faraone SV, Greenhill LL, Howes MJ, Secnik K, Spencer T, Ustun TB, Walters EE, Zaslavsky AM (2006) The prevalence and correlates of adult ADHD in the United States: results from the National Comorbidity Survey Replication. Am J Psychiatry 163:716-723.

Kobel M, Bechtel N, Specht K, Klarhöfer M, Weber P, Scheffler K, Opwis K, Penner IK (2010) Structural and functional imaging approaches in attention deficit/hyperactivity disorder: does the temporal lobe play a key role? Psychiatry Res 183:230-236.

Kuczenski R, Segal DS (1997) Effects of methylphenidate on extracellular dopamine, serotonin, and norepinephrine: comparison with amphetamine. J Neurochem 68:2032-2037.

Lammel S, Hetzel A, Häckel O, Jones I, Liss B, Roeper J (2008) Unique properties of mesoprefrontal neurons within a dual mesocorticolimbic dopamine system. Neuron 57:760-773.

Logan J, Fowler JS, Volkow ND, Wolf AP, Dewey SL, Schlyer DJ, MacGregor RR, Hitzemann R, Bendriem B, Gatley SJ, Christman DR (1990) Graphical analysis of reversible radioligand binding from time-activity measurements applied to $\left[\mathrm{N}-{ }^{11} \mathrm{C}\right.$-methyl]-(-)-cocaine PET studies in human subjects. J Cereb Blood Flow Metab 10:740-747.

Martinez D, Slifstein M, Broft A, Mawlawi O, Hwang DR, Huang Y, Cooper T, Kegeles L, Zarahn E, Abi-Dargham A, Haber SN, Laruelle M (2003) Imaging human mesolimbic dopamine transmission with positron emission tomography. Part II. Amphetamine-induced dopamine release in the functional subdivisions of the striatum. J Cereb Blood Flow Metab 23:285-300.

Modi NB, Lindemulder B, Gupta SK (2000) Single- and multiple-dose pharmacokinetics of an oral once-a-day osmotic controlled-release OROS (methylphenidate $\mathrm{HCl}$ ) formulation. J Clin Pharmacol 40: 379-388.

Molina BS, Hinshaw SP, Swanson JM, Arnold LE, Vitiello B, Jensen PS, Epstein JN, Hoza B, Hechtman L, Abikoff HB, Elliott GR, Greenhill LL, Newcorn JH, Wells KC, Wigal T, Gibbons RD, Hur K, Houck PR; MTA Cooperative Group (2009) The MTA at 8 years: prospective follow-up of children treated for combined-type ADHD in a multisite study. J Am Acad Child Adolesc Psychiatry 48:484-500.

Montgomery AJ, Asselin MC, Farde L, Grasby PM (2007) Measurement of methylphenidate-induced change in extrastriatal dopamine concentration using $\left[{ }^{11} \mathrm{C}\right]$ FLB 457 PET. J Cereb Blood Flow Metab 27:369-377.

Morón JA, Brockington A, Wise RA, Rocha BA, Hope BT (2002) Dopamine uptake through the norepinephrine transporter in brain regions with low levels of the dopamine transporter: evidence from knock-out mouse lines. J Neurosci 22:389-395.

National Institutes of Health (2000) National Institutes of Health Consensus Development Conference Statement: diagnosis and treatment of at- tention-deficit/hyperactivity disorder (ADHD). J Am Acad Child Adolesc Psychiatry 39:182-193.

Piccini P, Pavese N, Brooks DJ (2003) Endogenous dopamine release after pharmacological challenges in Parkinson's disease. Ann Neurol 53:647-653.

Prince J (2008) Catecholamine dysfunction in attention-deficit/hyperactivity disorder: an update. J Clin Psychopharmacol 28:S39-S45.

Rosa-Neto P, Lou HC, Cumming P, Pryds O, Karrebaek H, Lunding J, Gjedde A (2005) Methylphenidate-evoked changes in striatal dopamine correlate with inattention and impulsivity in adolescents with attention deficit hyperactivity disorder. Neuroimage 25:868-876.

Rösler M, Retz W, Stieglitz RD (2010) Psychopathological rating scales as efficacy parameters in adult ADHD treatment investigations: benchmarking instruments for international multicentre trials. Pharmacopsychiatry 43:92-98.

Rubia K, Halari R, Cubillo A, Mohammad AM, Brammer M, Taylor E (2009) Methylphenidate normalises activation and functional connectivity deficits in attention and motivation networks in medication-naive children with ADHD during a rewarded continuous performance task. Neuropharmacology 57:640-652.

Sesack SR, Hawrylak VA, Guido MA, Levey AI (1998) Cellular and subcellular localization of the dopamine transporter in rat cortex. Adv Pharmacol 42:171-174.

Sonuga-Barke EJ (2003) The dual pathway model of AD/HD: an elaboration of neuro-developmental characteristics. Neurosci Biobehav Rev 27:593-604.

Spencer TJ, Biederman J, Ciccone PE, Madras BK, Dougherty DD, Bonab AA, Livni E, Parasrampuria DA, Fischman AJ (2006) PET study examining pharmacokinetics, detection and likeability, and dopamine transporter receptor occupancy of short- and long-acting oral methylphenidate. Am J Psychiatry 163:387-395.

Stokes PR, Egerton A, Watson B, Reid A, Breen G, Lingford-Hughes A, Nutt DJ, Mehta MA (2010) Significant decreases in frontal and temporal $\left[{ }^{11} \mathrm{C}\right]$-raclopride binding after THC challenge. Neuroimage 52: 1521-1527.

Swanson J, Arnold LE, Kraemer H, Hechtman L, Molina B, Hinshaw S, Vitiello B, Jensen P, Steinhoff K, Lerner M, Greenhill L, Abikoff H, Wells K, Epstein J, Elliott G, Newcorn J, Hoza B, Wigal T; MTA Cooperative Group (2008) Evidence, interpretation, and qualification from multiple reports of long-term outcomes in the Multimodal Treatment Study of children with ADHD (MTA). Part II. Supporting details. . J Atten Disord 12:15-43.

Tilley MR, Gu HH (2008) The effects of methylphenidate on knockin mice with a methylphenidate-resistant dopamine transporter. J Pharmacol Exp Ther 327:554-560.

Tripp G, Wickens JR (2008) Research review: dopamine transfer deficit: a neurobiological theory of altered reinforcement mechanisms in ADHD. J Child Psychol Psychiatry 49:691-704.

Volkow ND, Wang GJ, Fowler JS, Logan J, Schlyer D, Hitzemann R, Lieberman J, Angrist B, Pappas N, MacGregor R, Burr G, Cooper T, Wolf AP (1994) Imaging endogenous dopamine competition with $\left[{ }^{11} \mathrm{C}\right]$ raclopride in the human brain. Synapse 16:255-262.

Volkow ND, Wang GJ, Fowler JS, Logan J, Gatley SJ, Hitzemann R, Chen AD, Dewey SL, Pappas N (1997) Decreased striatal dopaminergic responsiveness in detoxified cocaine-dependent subjects. Nature 386:830-833.

Volkow ND, Wang GJ, Fowler JS, Gatley SJ, Logan J, Ding YS, Hitzemann R, Pappas N (1998) Dopamine transporter occupancies in the human brain induced by therapeutic doses of oral methylphenidate. Am J Psychiatry 155:1325-1331.

Volkow ND, Wang G, Fowler JS, Logan J, Gerasimov M, Maynard L, Ding Y, Gatley SJ, Gifford A, Franceschi D (2001) Therapeutic doses of oral methylphenidate significantly increase extracellular dopamine in the human brain. J Neurosci 21:RC121(1-5).

Volkow ND, Wang GJ, Fowler JS, Logan J, Franceschi D, Maynard L, Ding YS, Gatley SJ, Gifford A, Zhu W, Swanson JM (2002) Relationship between blockade of dopamine transporters by oral methylphenidate and the increases in extracellular dopamine: therapeutic implications. Synapse 43:181-187.

Volkow ND, Wang GJ, Fowler JS, Telang F, Maynard L, Logan J, Gatley SJ, Pappas N, Wong C, Vaska P, Zhu W, Swanson JM (2004) Evidence that methylphenidate enhances the saliency of a mathematical task by increasing dopamine in the human brain. Am J Psychiatry 161:1173-1180. 
Volkow ND, Wang GJ, Newcorn J, Telang F, Solanto MV, Fowler JS, Logan J, Ma Y, Schulz K, Pradhan K, Wong C, Swanson JM (2007) Depressed dopamine activity in caudate and preliminary evidence of limbic involvement in adults with attention-deficit/hyperactivity disorder. Arch Gen Psychiatry 64:932-940.

Volkow ND, Wang GJ, Telang F, Fowler JS, Logan J, Wong C, Ma J, Pradhan K, Tomasi D, Thanos PK, Ferr é S, Jayne M (2008) Sleep deprivation decreases binding of $\left[{ }^{11} \mathrm{C}\right]$ raclopride to dopamine $\mathrm{D}_{2} / \mathrm{D}_{3}$ receptors in the human brain. J Neurosci 28:8454-8461.

Volkow ND, Wang GJ, Kollins SH, Wigal TL, Newcorn JH, Telang F, Fowler JS, Zhu W, Logan J, Ma Y, Pradhan K, Wong C, Swanson JM (2009) Evaluating dopamine reward pathway in ADHD: clinical implications. JAMA 302:1084-1091.

Volkow ND, Wang GJ, Newcorn JH, Kollins SH, Wigal TL, Telang F, Fowler JS, Goldstein RZ, Klein N, Logan J, Wong C, Swanson JM (2011) Moti- vation deficit in $\mathrm{ADHD}$ is associated with dysfunction of the dopamine reward pathway. Mol Psychiatry 16:1147-1154.

Wang GJ, Volkow ND, Levy AV, Fowler JS, Logan J, Alexoff D, Hitzemann RJ, Schyler DJ (1996) MR-PET image coregistration for quantitation of striatal dopamine D2 receptors. J Comput Assist Tomogr 20:423-428.

Wang GJ, Volkow ND, Wigal T, Kollins S, Newcorn J, Telang F, Logan J Wong C, Fowler JS, Swanson J (2009) Chronic treatment with methylphenidate increases dopamine transporter density in patients with attention deficit hyperactive disorder. J Nucl Med 50 [Suppl 2]:1283.

Wang GJ, Volkow ND, Fowler JS, Logan J, Pappas NR, Wong CT, Hitzemann RJ, Netusil N (1999) Reproducibility of repeated measures of endogenous dopamine competition with $\left[{ }^{11} \mathrm{C}\right]$ raclopride in the human brain in response to methylphenidate. J Nucl Med 40:1285-1291.

Wise RA (2002) Brain reward circuitry: insights from unsensed incentives. Neuron 36:229-240. 